\section{Digital transformation for higher education post COVID-19}

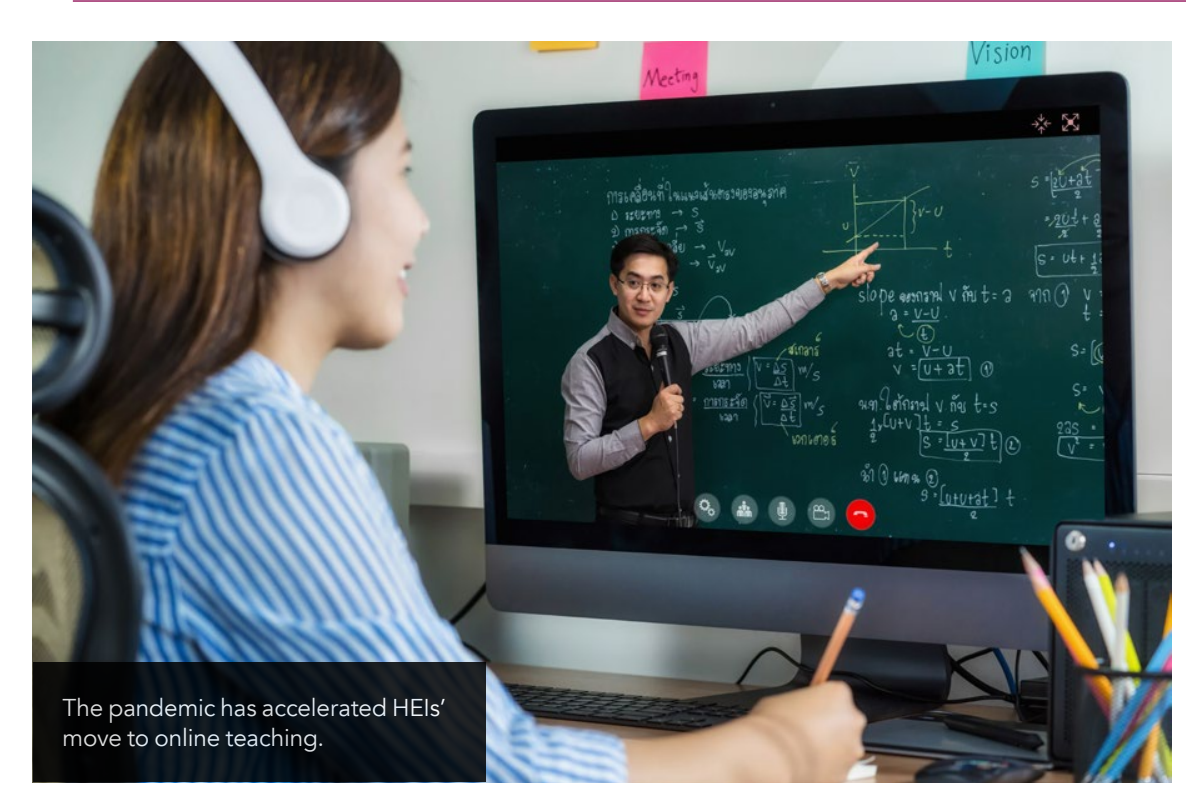

in HEls can be scaled to include internal who should understand and be able operations, strategic imperatives, of the costs invols not and the fact ent engagement." that HEls often struggle with financia resources, particularly in developing a digita

transformation
strategy if they

strategy if they
are to survive and

Digital transformation can help to on new research, Prof Waller argues that or otherwise in moving online depends on their digital readiness and resilience, transformation strategy. Prof Waller will look at what lessons can be learned trans decade of digital on face-to-face contact have meant that many of us have retreated to the confines of our homes and moved our lives online. It should therefore be no surprise that torecasting company Research \& Marke estimates that global spend on digital transformation will double from almost half a tillon US dollars in 2020 to more than a trillion in 2025.

Higher Education Institutions (HEls) are among those organisations who

\section{DIGITAL TRANSFORMATION}

AND HEls

Prof Waller defines digital transformation theory as explaining "how, and in what ways, digital technologies can be used processes ton organisation's business processes towards promoting positive which strategises digitalisation and digital
whe technologies, helping organisations to stay competitive and enhancing consumer experience. A "destination rather a journey", it is "business-led and technology-enabled".

Despite universities' involvement in technology design and production as a subject discipline, Prof Waller finds that HEls lag behind business in their uptake of digital technologies. The pandemic has accelerated their move to online teaching. and most Hels have incorporated some elements of digital transformation into their current and planned processes, but far more could be done.

Prof Waller explains: "The reality today is that digital transformation strategies methodology and purposive sampling literature on digital transformation and bowledge, is also aware of the wid polfical, and managerial implications of also be fully owned by senior leaders compete in the

brand new digital, post-CoVID
world."

\section{configure and reconfigure the business \\ EMPOWERING \\ PEOPLE} processes of HEls and bring them into the digital age.

Prof Waller used document analysis technique to evaluate the academic identify the lessons learned from 10 years by HEls Throe core themplementation by Hils. Theecore henes entrged: trect people, and the use of appropriate digita

\section{RELEVANT STRATEGY}

To make digital transformation a success, analysis revertis having a relevant and workable digital transformation to the institution's vision, mission and goals. The strategy should be led by a coordinator who, in addition to technical business, human relations, societal,

Prof Waller finds that the strategy must

Digital learning is

countries. HEls should therefore set priorities and consider partnerships with technology companies. Prof Wallor be wary, but stresses that technology companies can be natural parners. In exchange for financial support, Hels and bodies of students who can help to Time is also important Digtal transformation is a long process which comprises moving from physical to digita mprove processes, and finolyes to all the opportunities digitalisation offers. Recognising that universities often work in silos, digital transformation strategies must be more inclusive and involve key ust, understanding, agility, and safety".

arns HEls to be wary of "on-size-fits-all" approaches promoted only do HEls differ from each other, departments and even teams within an Instiction may vary. Prof Waller's resear suggests that the most successful addition, they require monitoring It

able to pivot when

necessary. only one way in which acknowledges that some HEls may

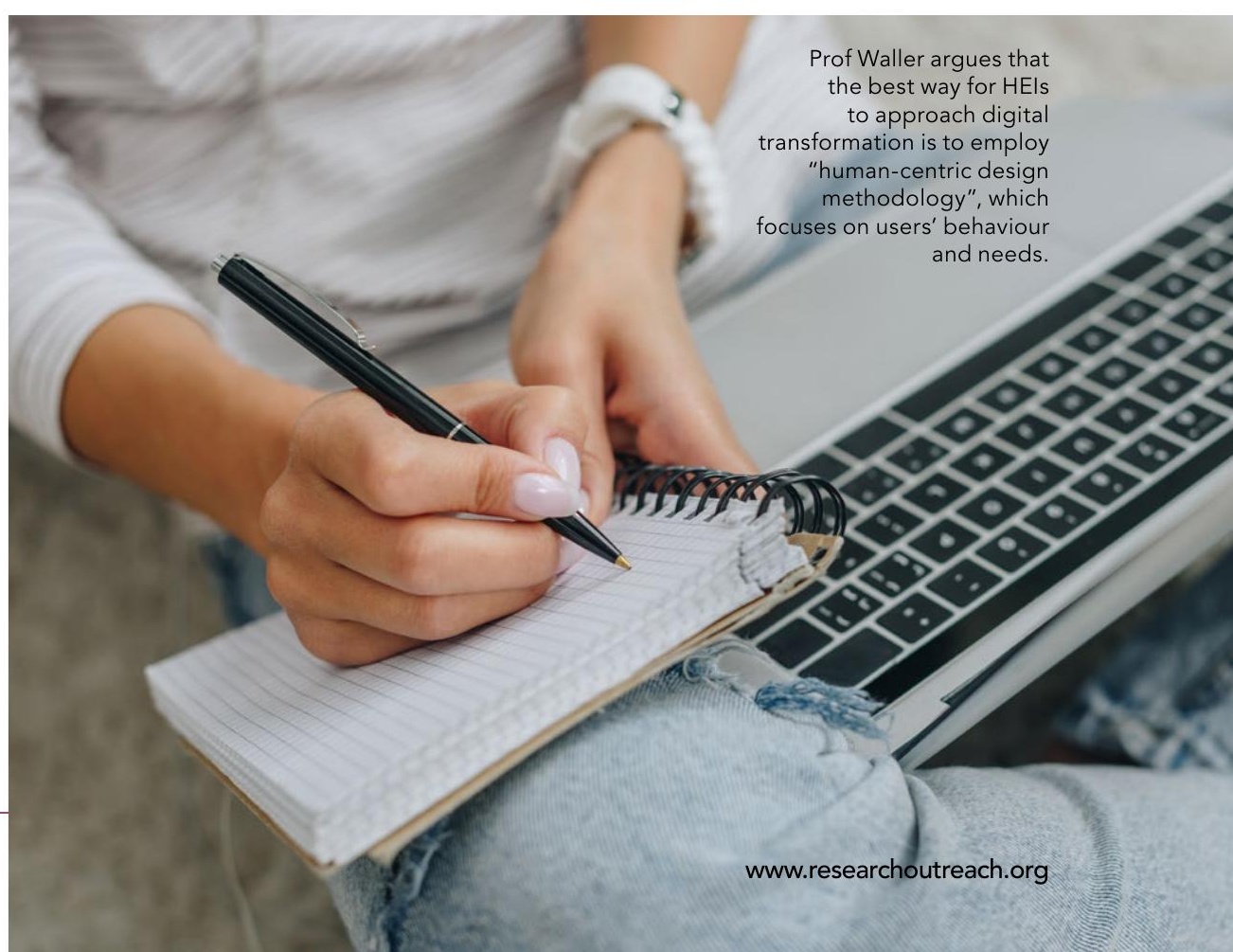




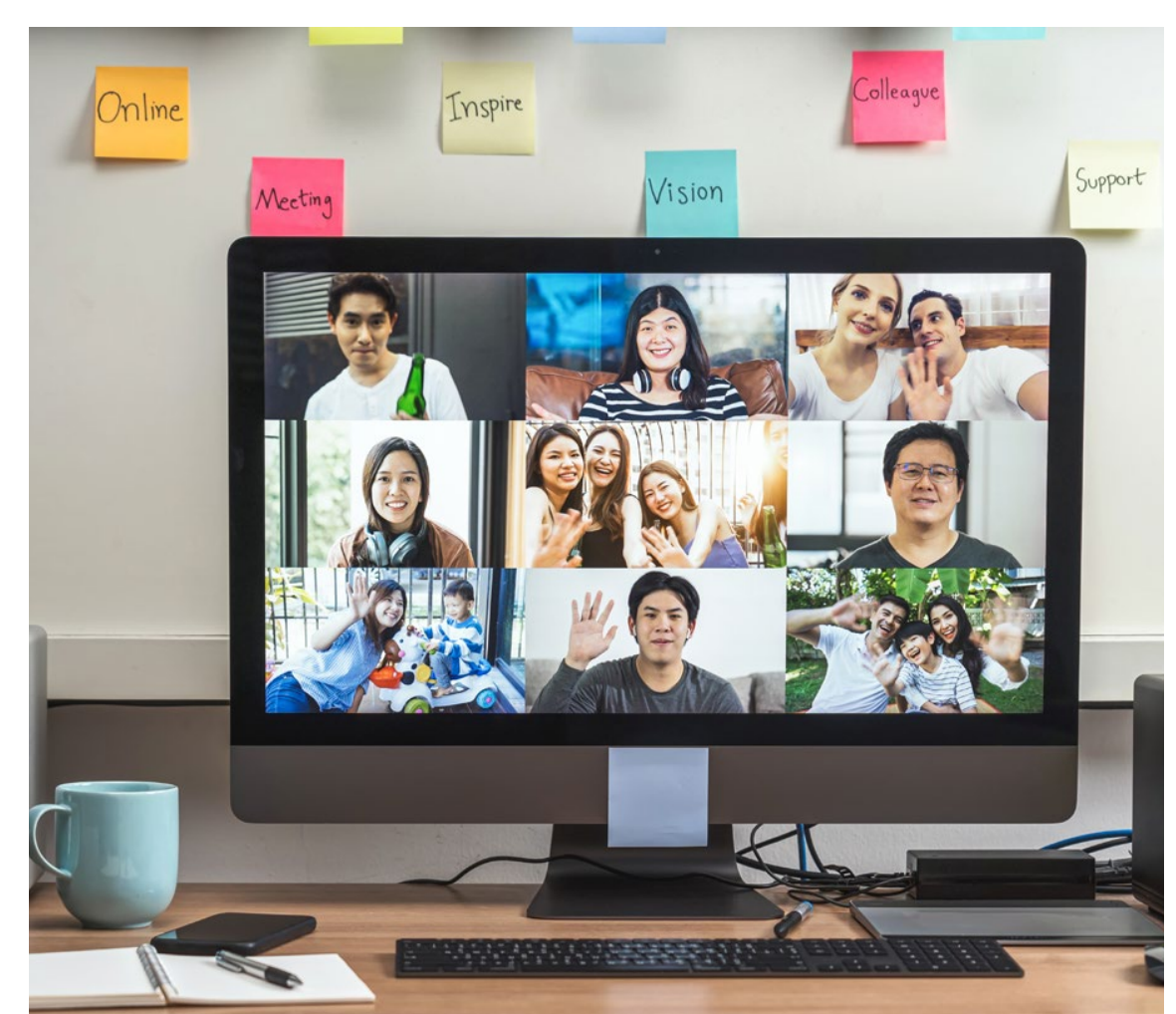

Digitat technologies can support the teaching, research and socied
and help them meet students' current and future expectations.

He warns that today's students are digital natives who expect HEls to have high digital standards and awareness of the importance of security and privacy. Prof Waller explains: "If an HEI wants to attract and retain students in a post-corona world, they will need to articulate and showcase their technological savviness, innovation capacity, and futuristic look-and-feel." To succeed HEls must also "align their organisational structure and culture to their digital transformation strategy". He It is about thinking and acting digitally. accepting digitalisation, and creating orientation towards digitalisation."

The process involves profound changes in teaching methodologies, competencies, and assessment. Though some staff may resist, the research suggests that staff must be empowered by being given the right tools, technologies, and training. Post-pandemic, even if face-to-face teaching returns, most HEls will continue to incorporate some degree of online learning. Prof Waller finds that digital transformation may demand a change management strategy which incorporas the need for changed

HEls also interact with society and, for example, the quality of a country's
Prof Waller argues that the best way for is to to approach digntal transformay methodolog" - a problem sosign methodology to help design interactive systems which focus on users' behaviv and needs. He explains: "Human-centric design is therefore the identification and understanding of human desires, context, needs to facilitate the development of better concepts, interfaces, systems, tools and more importantly a better experience for users, whether these users are students, faculty, staff, and/ or society."

RECONFIGURING PROCESSES Prof Waller's research suggests that, though HEls are at different stages on their digital transformation journeys, significant lessons can be learned from thers experience of implementing and becoming digital education institutions.

Digital technologies can support the general goals of HEls, namely teaching research and societal outreach, and provide them with the capabilities, knowledge and tools to meet students' current and future expectations. They will also need to implement digital al media, webinars and virtual

Digital transformation is a mindset. It is about thinking and acting digitally, accepting digitalisation, and creating an orientation towards digitalisation.

$\begin{array}{ll}\text { workshops, HEls can empower citizens } & \text { transformation strategies if they are } \\ \text { in other countries to use digital } & \text { to survive. Prof Waller argues that }\end{array}$ in other countries to use digital can also enable faculties to engage with other faculties and organisations worldwide, allowing people to access information and collaborate.

APPROPRIATE TECHNOLOGIES While digital transformation is about how people use technology, rather than the technologies themselves, research suggests that digital technologies can "make education more efficient, scalable and accessible". Prof Waller finds that these benefits "can make or break an institution" and HEls have to ensure th they choose appropriate technology and innovation which brings bene business models of transformation are problematic when applied to HEls, which need to find solutions appropriate to their needs and operations.

Prof Waller concludes: "Digital transformation can help to configure and reconfigure the business processes of HEls and bring them into the digital age, once they have identified the right strategy. "He adds: "The right strategy can only manifest itself with an understanding of the configurations, elements, processes, challenges, antecedents and, among other things, the actors, tools, objects, and systems necessary for successfully implementing
Research Objectives

Prof Lloyd George Waller researches digital transformation within Higher Education Institutions.

\section{Detail}

Bio

Lloyd Waller is a Professor of Digital Transformation Policy and Governance. He has a Masters in Sociology of Development from the University of the West Indies, Jamaica with a focus on electronic commerce (e-commerce), as well as a PhD in Social Policy from electronic tourism (e-tourism). Currently, he is located at the University of the West Indies, (Mona Campus) Kingston Jamaica. Professor Waller's area of research include Digital Transformation Policies and Practices, Electronic Governance, Governance, Tourism Resilience, Advanced Research Methods and well as Development Studies. Professor Waller has managed several national level digita transformation projects and consulted on global and regional projects. He has published and taught on issues related to digital transformation generally and digital transformation for Higher Education Institutions more specifically. He has also worked with several international organisations on vantous ICT for development initiatives well as those which focus on digital transformation.

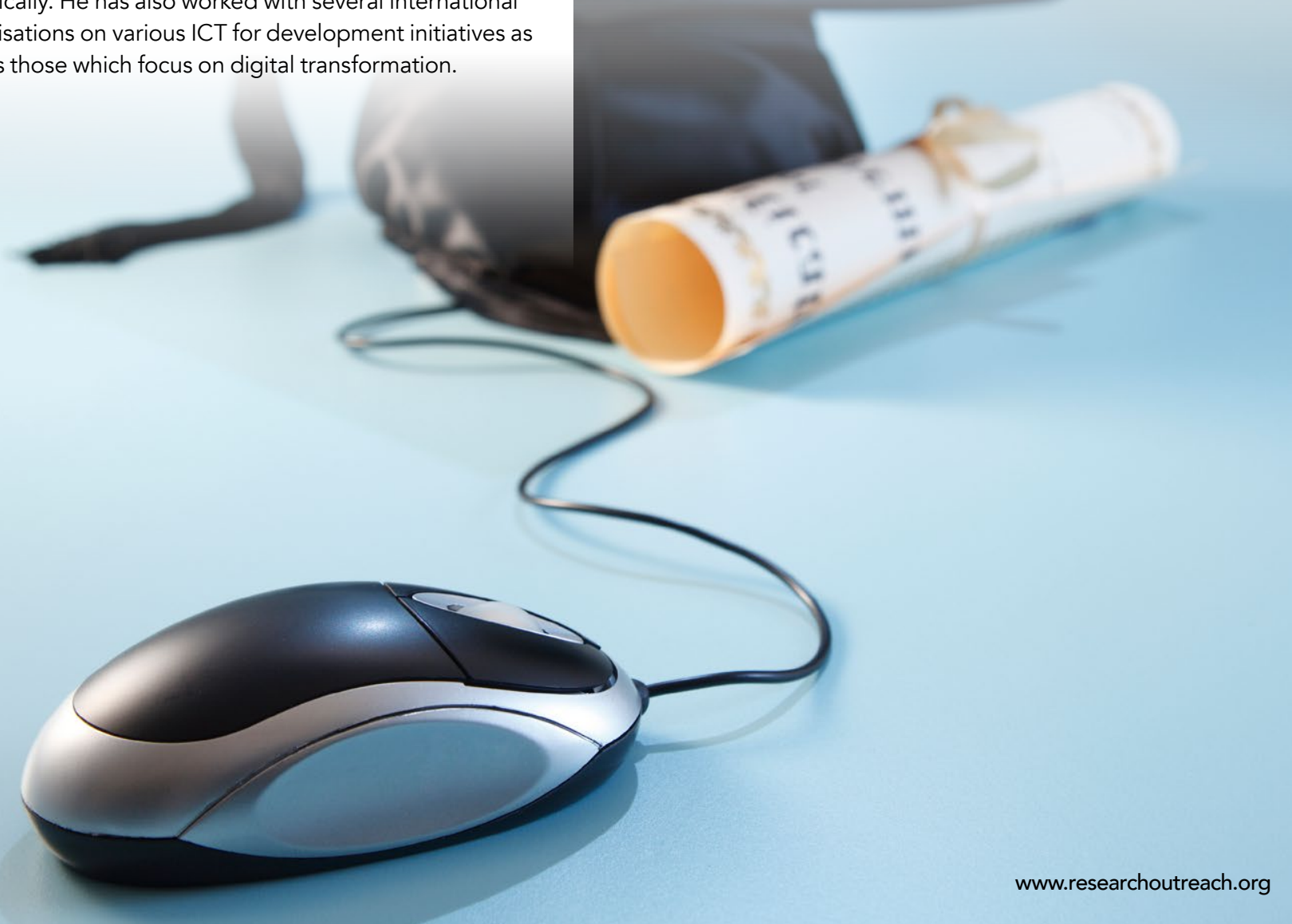

References

Digital Transformation: A framework for Higher Education Institutions [Forthcoming on Amazon October 2021]

\section{Personal Response}

What inspired you to conduct this research?

II Not much literature or practical data exists regarding book was written to bridge this gap and to provide no technological academics and technology consultants and firms with the information needed to successfully implement a Digital Transformation Strategy for Higher
Educational Institutions.

If you could offer just one single piece of advice to a pped HEl, what would it be?

II Think big, use emerging technology, and act fast. senior academic who understand the organisation. 